\title{
No FULGOR FRÁGIL DA EXISTÊNCIA, A SEDUÇÃo DO VISÍVEL E A PAIXÃo DO INVISÍVEL. EM memória de José Augusto Mourão
}

\author{
Moisés de Lemos Martins \\ moiseslmartins@gmail.com \\ Universidade do Minho, Centro de Estudos de Comunicação e Sociedade Campus de Gualtar, 4710-057 Braga, Portugal
}

\section{ReSUMO}

Apresento neste texto a trajetória pessoal, intelectual e académica, de José Augusto Mourão (1948-2011), professor de Semiótica na Universidade Nova de Lisboa.

\section{PALAVRAS-Chave}

Semiótica; texto e textualidade; estruturalismo; Algirdas Greimas; estruturas morfogenéticas e morfodinâmicas; teoria das catástrofes; textualidade bíblica; Ordem dos Pregadores

\section{INTRODUÇÃo}

"Bem-aventurado sejas tu, ó texto" - é este o ensaio de abertura do livro de homilias Quem Vigia o Vento não Semeia (2011), que José Augusto Mourão já não chegou a ver publicado em vida. Semiólogo, teólogo, poeta, músico, crítico literário e ensaísta, José Augusto Mourão foi toda a vida um textualista. O texto e a escrita foram os seus mediadores da "experiência". Usou-os como defesas contra a imediaticidade, a efusão passional, o intuicionismo.

José Augusto Mourão foi frade dominicano. Estive com ele vezes sem conta em atos litúrgicos, que assinalam a ritualidade da vida, umas vezes como celebração da alegria, da festa e da promessa, outras como manifestação de tristeza, sofrimento e morte. A sua palavra era a rememoração da palavra essencial, uma palavra que percorria os lugares do invisível do visível, e que era também um trabalho de resistência, onde se estabelecia o sentido da comunidade, que sempre colocou no horizonte. Mas a sua pregação não se desviava nunca do mesmo padrão: tratava-se da leitura de textos, meticulosamente pensados e escritos. A Palavra e o Espelho (2000) e Quem Vigia o Vento não Semeia (2011) são coletâneas homiléticas, que exprimem a adesão de José Augusto Mourão à mediação da escrita, mesmo na parenética. Foi, com efeito, para esse plano, o do texto, que todas as suas filiações intelectuais convergiram.

\section{O TEXTO E A TEXTUALIDADE}

As anáforas da liturgia católica constituíram os primeiros objetos do estudo semiótico de José Augusto Mourão. E foi François Genuyt quem o introduziu nos estudos da escola greimasiana, sendo seu orientador na licenciatura, que concluiu na Faculdade de 
Teologia de Lyon, em 1977. Depois, fez análise de textos bíblicos, particularmente textos do Novo Testamento. Em 1991, traduziu e introduziu o livro de Jean-Claude Giroud e de Louis Panier, Semiótica - Uma Prática de Leitura e de Análise dos Textos Bíblicos (Lisboa, Difusora Bíblica). E em 1999, já no auge de uma carreira académica, que iniciara em 1981 na Universidade Nova de Lisboa e agora o levava às provas de agregação na mesma Universidade, ainda organizou a coletânea Semiótica e Bíblia, publicada nas Edições Paulinas. Aí são apresentados estudos de Ívan Almeida, Jean Delorme, François Genuyt, Jean Calloud, Louis Panier, François Martin e Cécile Turiot.

Por essa época, já o semiólogo José Augusto Mourão publicara trabalhos de grande fôlego, teórico e analítico, designadamente aqueles que produziu sobre textos místicos da tradição cristã, como por exemplo A Visão de Túndalo. Da Fornalha de Ferro à Cidade de Deus (1988) e Sujeito, Paixão e Discurso. Trabalhos de Jesus (1996), neste caso analisando textos de fr. Tomé de Jesus e apresentando em livro a tese de doutoramento, que havia defendido em 1991, na Universidade Nova de Lisboa. Em A Sedução do Real Literatura e Semiótica (1998), regressa com a "Visão de Túndalo" e ocupa-se ainda dos Trabalhos de Jesus, mantendo todavia alguns pequenos fragmentos que têm a marca das suas primeiras escolhas textualistas.

Entretanto, em 2001, organizou, com Maria Augusta Babo, O Campo da Semióti$c a$, um significativo número da Revista de Comunicação e Linguagens. Além de autores portugueses, que se juntaram a José Augusto Mourão e a Maria Augusta Babo, como Luís Carmelo, António Fidalgo, Pedro Barbosa, António Machuco Rosa, Aníbal Alves, Fernando Belo e eu próprio, escrevem também nesse número da $\mathrm{RCL}$, entre outros, Lúcia Santaella, Winfred Nöth, Thomas Sebeok, Herman Parret, Jacques Fontanille, Eric Landowski e Norma Tasca.

Acontece, no entanto, que José Augusto Mourão também é poeta. É o poeta de Vazio Verde (1985), de Dizer-Deus - Ao (Des)abrigo do Nome (1991) e de O Nome e a For$m a$ (2011). É, pois, com naturalidade que a poesia, aliás, a literatura em geral, se tenha tornado, igualmente, objeto da sua prática semiótica. Em A Sedução do Real esta escolha aparece abundantemente: Torga, Celan e Duras, Beckett, Saramago, Vergílio Ferreira, Maria Gabriela Lansol, Herberto Helder, Bernardim Ribeiro, Bernardino de Santa Rosa. Mas escreveu, sobretudo, O Fulgor é Móvel. Em torno da Obra de Maria Gabriela Llansol (2003) e, com outros autores, Natália Correia. A Festa da Escrita (2010).

José Augusto Mourão começou a trabalhar como semiólogo, analisando textos da comunidade e da tradição cristãs, em que nasceu e que o apaixonaram. E foi por se sentir membro de uma comunidade e de uma tradição cristãs, que a sua prática semiótica o levou a confrontar-se com textos literários, de Saramago, a Beckett, a Duras e a Eugénio de Andrade, de Proust a Vergílio Ferreira, a Celan e a Torga, ou então, com textos filosóficos, como os de Tomás de Aquino. É que não existe memória que não suscite um corpo, nem palavra nova "que não venha marcada pelo fogo ou pelo vento", como chegou a escrever.

\section{EM DEFESA DO MÉTODO}

A inclinação de José Augusto Mourão pela textualidade veio a ganhar novos contornos e a conhecer novas articulações, quando se interessou pelos fenómenos da 
comunicação, muito particularmente pela comunicação eletrónica. Em A Sedução do Real, a sua mestria espraiou-se pela análise do rap, dos reality shows e do tabaco. Mas a sua obra principal sobre a comunicação na modernidade é $O$ Mundo e os Modos da Comunicação, que publicou em 2006, sendo com Para uma Poética do Hipertexto. Fiç̧ão Interactiva (2001) e com Textualidade Electrónica. Literatura e Hiperfiç̧ão (2009) que José Augusto Mourão abraça as novas textualidades digitais.

Em José Augusto Mourão existe, então, este primeiro aspeto que singulariza a sua obra: trata-se de um textualista que desconfia e resiste à palavra "experiência". A sua intempestividade, e José Augusto Mourão foi um intempestivo, é sempre mediada pelo texto e pela escrita. No entanto, sendo um textualista, este presbítero, que foi frade da Ordem de São Domingos, não se identifica com a tese hermenêutica, que talvez maior entusiasmo suscita nos dias de hoje, e que podemos formular nos seguintes termos, de efeito retórico: não há experiência da verdade que não seja ato interpretativo, isto é, não há experiência de verdade que não seja ato de leitura.

José Augusto Mourão foi um moderno, pelo que o "pensamento mole" da renúncia a qualquer razão fundacional apenas o podia irritar. E foi por este diapasão que afinou a sua obra inteira: os seus textos são modernos, o que quer dizer, críticos, de racionalidade forte. Neles não há lugar para o indiferentismo relativista, para "a ideia de que só há interpretações" (Mourão, 1998: 156). Os charlatães do inefável, designação por si utilizada para nomear os pragmatistas, "abrem a porta de serviço do delírio e dizem: todas as perspetivas são equivalentes!” (Ibid.: 85). E logo concluiu, mas num mundo em que tudo se equivalesse, nada teria sentido, tudo seria insignificante.

A proposta semiótica de José Augusto Mourão é uma proposta crítica. E uma vez que a crítica não é neutra, do ponto de vista axiológico, os discursos apenas podem hierarquizar-se. Esta conclusão está estritamente associada ao entendimento dialógico da crítica, próprio de Mikhail Bakhtin. Neste entendimento, a experiência do texto, tanto inclui a experiência do limite da comunicação, como inclui também tudo o que nos religa, tudo o que é abertura a uma alteridade. Pois bem, diante do assalto da pós-modernidade, seja com a desconstrução de Derrida, que radicaliza a "Destruktion" de Heidegger e nos instala num paganismo sofista, seja com a pragmática de Rorty, que radicaliza o perspetivismo de Nietzsche e nos leva a pensar sem origem e sem fim, sem Génese e sem Apocalipse, a obra de José Augusto Mourão é, pela crítica dialógica, uma recusa do abandono dos critérios de juízo último.

À indiferença relativista, José Augusto Mourão opõe então a crítica dialógica. Mas é com este mesmo procedimento que combate o historicismo, essa surdez dogmática que se atola no dever-ser de um discurso estabelecido, a partir de um ponto de vista ideológico e moral. Como bem assinala, aí o texto nada tem a dizer-nos; apenas tem que entrar na nossa teoria.

Sabemos a que ponto José Augusto Mourão foi um cultor do método. Justificou-o nos seguintes termos: “O reducionismo da 'coisa literária' é defensável, pelo menos do ponto de vista metodológico" (Mourão, 1998: 14). E irrita-se com aquilo a que chama "a versão terrorista em relação a qualquer espécie de método" (Ibidem). Noutro passo de 
A Sedução do Real, depois de assinalar que não é um juiz do gosto e que não costuma pronunciar-se em termos estéticos sobre um dado texto ou obra, diz também o seguinte: "Prefiro [...] o lugar semiótico que analisa textos, explicando o funcionamento interno da combinatória de signos de que são feitos, os sistemas gerais a partir de que se concretizam, as articulações dos vários planos de estruturação e de geração de sentido. Esta opção metodológica implica que se renuncie à busca indefinida de hipotéticas determinações extra-linguísticas e se adopte uma óptica generativa e não genética de produção e de funcionamento de textos. Servir-me-ei, pois, do saber-fazer do semiótico para indicar o lugar onde o comentário crítico perca a inocência que proclama, simulando-lhe os processos, o fazer" (Ibid.: 93-94).

Aqui está a defesa do método, feita com a maior energia e intrepidez. Penso, no entanto, que o método é uma difícil ascese, a que se dedicam apenas os mais audazes e os mais resistentes, sendo que José Augusto Mourão tinha essas qualidades, de analista resistente e de hermeneuta audaz. Mas não deixa de ser surpreendente que o poeta de Vazio Verde, de Dizer-Deus - ao (Des)abrigo do Nome e de O Nome e a Forma possa ser também o autor de escritos ásperos e rugosos, talhados pelo bisturi da escola de $\mathrm{Pa}$ ris, talhados, para retomar as suas palavras, pelo "saber-fazer semiótico", entendido na ótica generativa da produção e funcionamento dos textos. Sempre constituiu para mim uma surpresa, é um facto, que o renovador, desde meados da década de oitenta, dos pesados rituais da liturgia católica, pela música coral polifónica e pela criação poética, pudesse colocar-se no trilho das categorias da semiótica narrativa e modal de Algirdas Julien Greimas.

Foi a resistência do real que o seduziu e o tornou um asceta do método, enfim, do conhecimento controlado. Por essa razão José Augusto Mourão se decidiu a investir numa perspetiva imanentista do sentido. Greimas e a escola de Paris, primeiro, Per Aage Brandt e Jean Petitot, depois, tornaram-se, entre outros, os seus companheiros de viagem, o que dá a alguns dos seus textos o aspeto de verdadeiras fortalezas inexpugnáveis, de tal maneira neles é densa a teia das estruturas lógico-semióticas e das formas sémio-físicas. Semiótica. Genealogias e Cartografias, obra feita em parceria com Maria Augusta Babo e publicada na Minerva, em 2007, constitui uma boa ilustração desta orientação teórica, tendo José Augusto Mourão retomado, aliás, uma parte significativa dos textos com que se apresentou a provas de agregação, em 1999'.

\section{AS FIGURAS DO EXPLORADOR E DO MISSIONÁRIO}

Diga-se, no entanto, em abono da verdade, que felizmente a parte mais significativa da obra de José Augusto Mourão não ilustra este procedimento. Se o real sempre seduziu José Augusto Mourão, prescrevendo-Ihe o método, também o seduziu pelo seu

\footnotetext{
' Em A Linguagem, a Verdade e o Poder. Ensaio de Semiótica Social, obra que publiquei em 2002 (Lisboa: Fundação Calouste Gulbenkian/Fundação para a Ciência e a Tecnologia), fiz sob a epígrafe "Para uma physis fenomenológica" (pp. 47-57), uma leitura crítica da obra de José Augusto Mourão, centrando-me particularmente nos textos que apresentou a provas de agregação. Mas já havia apresentado, com o título "Sobre o impacto de uma physis fenomenológica", uma comunicação ao II Congresso da Sopcom, realizado em Lisboa, em 2001. Veja-se, Repositorium da UM: http://hdl.handle.net/1822/25334
} 
resto, por aquilo que não se deixava controlar. Por essa razão, este semiólogo da Ordem dos Pregadores foi sempre, também, um explorador de sinais que nos indicam as leis que nos transcendem. Hoje, estou em crer que Greimas e a escola de Paris foram para si um acaso, embora um acaso convertido depois numa escolha, continuamente renovada.

Tendo presente a totalidade da obra de José Augusto Mourão fico com a impressão de que há nela uma confiança num fundo de interpretação mais resistente e mais profundo que as estruturas morfodinâmicas e morfogenéticas, em que fundou muitas das suas análises, confiança essa que vem de mais longe que a própria crítica. A crítica é sempre articulada a partir de metodologias, de técnicas e de horizontes teóricos domináveis. Parece-me, no entanto, que é a confiança colocada nessa doação de sentido anterior à própria crítica, que constitui José Augusto Mourão como sujeito recetor e como sujeito crítico.

É talvez por esta razão, por acolher um fundo de interpretação mais resistente que a própria crítica, que José Augusto Mourão preferiu rever-se na figura do explorador, e não tanto na figura do missionário. A figura do explorador evoca uma essência (palavra que não evita) e propõe uma abertura. Aliás, é também uma abertura que é figurada pela expressão de "infra-estruturas quase transcendentais que nos asseguram que de cada vez [que lemos um texto literário] algo de indecidível se tocou, deixando ao leitor a liberdade de escolha" (Mourão, 1998: 15). Essa abertura parece-me ainda insinuada, quando José Augusto Mourão refere: "o tom, quer de escrita, quer da leitura, obedece ao regime de uma apocalíptica sem outra escatologia que o tom do 'vem', para além do bem e do mal" (Ibid.: 15). Dir-se-ia que a errância, o indeterminado, o indecidível e o figural, nos colocam perante um "imanentismo aberto", expressão que adopta de Kerbrat-Orecchioni e de Jean-Claude Coquet.

Podemos dizer que em José Augusto Mourão o algoritmo se casou sempre bem com a metáfora, ou seja, que o discurso vigiado se casou sempre bem com o seu resto. Com efeito, nele, o analista não foi nunca o burocrata ou o parasita da escrita. Pelo contrário, o analista foi um explorador de novas conjeturas interpretativas, foi sempre um criador. Bem sabemos que tanto a morfogénese como a morfodinâmica, que cultivou, surgem na esteira da teoria matemática das catástrofes, de René Thom, que é uma teoria geral das formas, tanto linguísticas, como naturais. Mas se os números chegam a ser questão na sua obra trata-se dos números do "deus geómetra", de Timeu, números quais palavras, que ordenam o cosmos, dando-lhe proporção, equilíbrio e justiça. Ou seja, em José Augusto Mourão, a força da metáfora sobrepôs-se, por regra, ao algoritmo.

E eu penso, aliás, que não se perdeu nada, sempre que os textos de José Augusto Mourão não foram análises perfeitamente canónicas. É certo que ele teria gostado que fossem, não sei se confessando algum receio, se pedindo ao leitor que o desculpasse. Para dar um exemplo, não se perde nada em A Sedução do Real consistir em "algumas traições" relativamente a esse "lugar semiótico que analisa textos" (Mourão, 1998: 94). Penso, aliás, que lá onde os textos de José Augusto Mourão mantêm o caráter de uma análise ainda canónica, menos interessará o leitor. 
Fiel à natureza da linguagem, o que quer dizer, ao seu caráter dialógico, José Augusto Mourão mostra-nos na sua obra que aquilo que se exprime na linguagem não é simplesmente a fixação de um querer dizer. Aquilo que se exprime na linguagem é também "uma tentativa em constante transformação, ou melhor, uma tentação sempre repetida de se comprometer em algo, através do diálogo. O que significa que nos expomos" (Mourão, 1998: 25). Pela escrita expomo-nos. Na obra de José Augusto Mourão aprendemos, com efeito, que a palavra, em vez de validar os nossos preconceitos, põe-nos em jogo, submetendo-os à nossa dúvida e à réplica do outro. É esse, aliás, o sentido da crítica dialógica.

Surpreende, assim, que aquele que julgávamos ser o missionário da exegese greimasiana, que é um mundo de contornos estreitos e ásperos, seja antes um explorador de mundos, um explorador de novos modos de existência e de novas formas de vida. Em José Augusto Mourão cumpre-se, exatamente, aquilo que ele próprio diz dos grandes escritores: "O estilo de um grande escritor é sempre também um estilo de vida, não como algo de pessoal, mas como invenção de uma possibilidade de vida, de um modo de existência. O artista sabe que quando termina uma obra, só então começa verdadeiramente a vida desta. Só quando reencontrada, interrogada, 'ingerida' por outrem, ele provocará naquele que a lê essa mudança interior que virá misteriosamente enriquecê-lo" (Mourão, 1998: 66-67).

Isto diz José Augusto Mourão dos grandes escritores, mas são as exatas palavras que encontrei para falar da sua obra: a proposta de um estilo de vida, a invenção de um modo de existência. José Augusto Mourão é um homem de crítica e de convicção, pelo que a sua obra é a de um moderno, uma obra com exigência ética. Diante do conflito das interpretações, em que resulta a guerra dos paradigmas, a exigência ética impõe-se como a "necessidade de uma arbitragem".

A proposta de José Augusto Mourão é assim uma "ética de leitura", uma ética que recusa o "momento sofista" e "pagão", pelo qual Jean-François Lyotard é de alguma forma o responsável, ou seja, uma ética que não se conforma com o "abandono de qualquer prescrição ou de critérios de juízo último" (Mourão, 1998: 67).

Crítica e ética. São essas duas dimensões que dão o sentido do movimento que José Augusto Mourão imprime à leitura, seja quando analisa textos de fr. Tomé de Jesus, Saramago, Torga, Celan ou Duras, seja quando faz trabalho de pretensão teórica.

É esta racionalidade forte, a racionalidade de um moderno com exigência ética, que faz explodir José Augusto Mourão diante da tibieza: "Como pode um pensamento mole, que renunciou à razão fundacional, que se tornou memória e fundo-sem-fundo, vir a ser consciência moral?", interroga-se em a Sedução do Real (Ibid.:73). De facto, José Augusto Mourão até pode compreender "o medo que desencadeia a ideia de análise" (Ibid.: 72), uma vez que se trata aí de uma dissolução. Mas a tibieza, essa, não é compreensível para si. Os tíbios aborrecem-no e vomita-os. Concorda, assim, com o diagnóstico de Michel de Certeau: "As convicções tornam-se moles, perdem os seus contornos e vamos encontrá-las na linguagem comum de um exotismo mental, numa koiné de ficção; as convicções acumulam-se na região em que se diz o que já se não faz, 
onde se teatralizam os quesitos que deixaram de ser pensáveis, onde se misturam as 'necessidades' variadas, ainda irredutíveis, mas completamente desprovidas de representações credíveis" (Ibid.: 156).

Falava Michel de Certeau da alma que desertou das convicções. José Augusto Mourão acolhe o seu diagnóstico, assumindo-o como uma recusa deste momento sofista e pagão, deste mundo fechado, que é o do abandono de todos os critérios de juízo último. Contra a indiferença, o homem de convicção faz pois confiança a uma abertura, a qual, glosando Derrida, é para ser lida "simultaneamente no sentido de sistema não fechado, de abertura deixada à liberdade do outro, e de abertura do convite feito ao outro" (Ibd.: 160).

\section{NotAS FINAIS}

Acolhendo a sugestão que me é dada pela figura da abertura, concluo o meu ponto de vista com uma última interrogação: que outro interesse tem José Augusto Mourão em frequentar analiticamente Vergílio Ferreira, Gabriela Llansol, Ângelo Monteiro, Herberto Helder, Torga, Natália Correia, Saramago, Celan, Duras... além do facto de eles exprimirem, todos, a seu modo, esta paixão comum da passagem infinita para um algures e um outro, enquanto nos dão o presente como um enigma?

Com uma obra monumental ${ }^{2}$, que declina o fulgor frágil da existência e manifesta as vertigens do humano, e com uma escrita que soa em nós como vergastadas contra a erosão do tempo e as cobardias humanas, José Augusto Mourão tornou-se em Portugal a maior referência nos estudos e no ensino da Semiótica, tendo sido membro do Comité executivo da Associação Internacional de Estudos Semióticos, a partir de 1999, e Coordenador do Grupo de Trabalho (GT) de Semiótica, que fundou, em 2009, na Associação Portuguesa de Ciências da Comunicação (SOPCOM).

Sempre pensei que a este corredor incansável, que toda a vida alimentou com novas conjeturas a fonte de onde corria, chegaria o tempo de ver reconhecida a importância da sua obra, nascida desse ponto incerto onde se intersetam a semiótica, a hermenêutica, a crítica literária, a filosofia e a teoria da literatura. Acredito que esse momento possa ter chegado, embora demasiado tarde para lhe fazer justiça em vida.

\section{Obras de José Augusto Mourão referidas neste texto}

2011, Quem Vigia o Vento não Semeia. Lisboa: Pedra Angular.

2010, Dicionário histórico das ordens e instituições afins em Portugal. Coordenador da edição, com José Eduardo Franco e Ana Cristina da Costa Gomes. Lisboa: Gradiva.

2010, Natália Correia. A Festa da Escrita. Co-organização do volume. Lisboa: Colibri.

\footnotetext{
${ }^{2} E$ É, igualmente, a todos os títulos majestosa, uma das últimas obras em que cooperou como co-editor e autor. Refiro-me ao Dicionário histórico das ordens e instituições afins em Portugal, publicado pela Gradiva, em 2010, sendo editores, José Eduardo Franco, José Augusto Mourão e Ana Cristina da Costa Gomes. Durante aproximadamente seis anos trabalharam nele cerca de três centenas de autores. Além disso, a obra tem 1019 páginas e o seu objeto são 368 instituições, agregadas em sete secções, estando uma delas subdividida em cinco subsecções.
} 
2009, O Nome e a Forma. Lisboa: Pedra Angular.

2009, Textualidade Electrónica. Literatura e Hiperficção. Lisboa: Vega.

2007, Semiótica. Genealogias e Cartografias. De parceria com Maria Augusta Babo. Coimbra: Minerva.

2006, O Mundo e os Modos de Comunicação. Coimbra: Minerva.

2003, O Fulgor é Móvel. Em torno da Obra de Maria Gabriela Llansol. Lisboa: Roma Editora.

2001, O Campo da Semiótica. Organização com Maria Augusta Babo, da Revista de Comunicação e Linguagens,

n. 29.

2001, Ficção Interactiva. Para uma Poética do Hipertexto. Lisboa: Edições Universitárias Lusófonas.

2000, A Palavra e o Espelho. Lisboa: Edições Paulinas.

1999, Semiótica e Bíblia. Organização do volume. Lisboa: Edições Paulinas.

1998, A Sedução do Real. Literatura e Semiótica. Lisboa: Vega.

1996, Sujeito, Paixão e Discurso. Trabalhos de Jesus. Lisboa: Vega.

1991, Jean-Claude Giroud e Louis Panier, Semiótica - Uma Prática de Leitura e de Análise dos Textos Bíblicos. Lisboa: Difusora Bíblica. Tradução e introdução de José Augusto Mourão.

1991, Dizer Deus - ao (Des)abrigo do Nome. Lisboa: Difusora Bíblica.

1988, A Visão de Túndalo. Da Fornalha de Ferro à Cidade de Deus. Lisboa: INIC.

1985, Vazio Verde - O Nome. Lisboa: CRC.

\section{REFERÊNCIAS}

Martins, M. de L. (2005) "Sobre o Impacto de uma Physis Fenomenológica na Semiótica", Novos Rumos da Comunicação, Atas do II Congresso da Sopcom, Lisboa, 2001, disponível em https://repositorium. sdum.uminho.pt/handle/1822/25334.

Martins, M. de L. (2004) Semiótica, Braga: Universidade do Minho, disponível em https://repositorium. sdum.uminho.pt/handle/1822/996

Martins, M. de L (2002) A Linguagem, a Verdade e o Poder. Ensaio de Semiótica Social, Lisboa: Fundação Calouste Gulbenkian \& Fundação para a Ciência e a Tecnologia.

头次火

Recebido a 15-07-2014

Aceite a 06-10-2014 